Research Article

\title{
Research on the Impact of Environmental Regulation on Enterprise Innovation from the Perspective of Official Communication
}

\author{
Lili Feng $\left(\mathbb{1},{ }^{1}\right.$ Lin Wang $\left(\mathbb{D},{ }^{2}\right.$ and Wenjun Zhou $(\mathbb{1})^{1}$ \\ ${ }^{1}$ School of Management, Hebei GEO University, Shijiazhuang 050031, China \\ ${ }^{2}$ Northeastern University at Qinhuangdao, Qinhuangdao 066000, China \\ Correspondence should be addressed to Wenjun Zhou; zhouwenjun@hgu.edu.cn
}

Received 17 May 2021; Accepted 20 July 2021; Published 2 August 2021

Academic Editor: Daqing Gong

Copyright ( $\odot 2021$ Lili Feng et al. This is an open access article distributed under the Creative Commons Attribution License, which permits unrestricted use, distribution, and reproduction in any medium, provided the original work is properly cited.

\begin{abstract}
Many developing countries including China are implementing increasingly stringent environmental regulations to achieve sustainable development. However, we have limited understanding about whether environmental regulations promote enterprise innovation. To address this research gap, this study empirically analyzes the impact of environmental regulations which is represented by the China Environmental Protection Law (2015) on enterprise innovation and it explores the moderating effects of official communication on environmental regulations and corporate innovation. The Super-Slacks-Based Measure (Super-SBM) model and Multiple Nonlinear Regression model are used to analyze 34,074 samples in China's A-share market during the 2015-2017 period. Our results show that, in general, a higher intensity of environmental regulations is more beneficial to incentivize enterprises to implement innovation. Meanwhile, there is an inverted U-type relationship between official communication and innovation of enterprises. Furthermore, at present, the average level of official communication in China is too high, which will weaken the role of environmental regulation in promoting enterprise innovation. Overall, this study can help us better understand the politics behind enterprise innovation in countries.
\end{abstract}

\section{Introduction}

After reformation and opening, China's economy has achieved world-renowned achievements. Unfortunately, due to the lack of innovation capabilities of Chinese companies, the sustainability of China's economic growth is worrying [1]. In particular, the performance of Huawei and ZTE is completely different in the Sino-US trade war in 2019, which makes us fully aware of the importance of corporate innovation capabilities [2]. However, according to the Bloomberg Innovation Index published in 2018, China is only ranked 19th, which reflects that China's scientific research innovation capacity still needs to be strengthened. Therefore, it is particularly important to study the influencing factors of enterprise innovation.

First of all, environmental pollution and ecological imbalance have become a serious threat to human survival. With the development of economy and the advancement of industrialization and urbanization, China's ecological environment has been seriously damaged. In the Global Environmental Performance Index (EPI) ranking of 2020, China ranks 120th out of 180 countries and regions with 37.3 points [3], which reflects not only the severity of China's environmental pollution, but also the relatively weak intensity of environmental regulation. Therefore, it is an inevitable choice for China to strengthen environmental regulation. However, China is still a developing country. At the same time of transforming the economic development mode, it should realize the coordinated development of environmental regulation and technological innovation by strengthening environmental protection. Technological innovation is the decisive factor to achieve the "win-win" goal of environmental protection and economic development, and the impact of environmental regulation on technological innovation has always been a hot research issue $[4,5]$. 
Secondly, official communication has been regarded by many scholars as an important reason for China's long-term sustained and rapid economic growth. In the new era, official communication will continue to be an important driving force for high-quality economic development and corporate innovation. The political shock caused by the change of officials can effectively enhance the willingness and intensity of innovation of enterprises. The change of officials had a clear positive effect on regional innovation capabilities [6]. However, some scholars had come to the opposite conclusion that the replacement of officials can cause policy uncertainty, increase corporate risks, and inhibit corporate innovation $[7,8]$. In addition, some scholars believed that the period of official communication was related to corporate innovation. Official remote communication would inhibit corporate $\mathrm{R} \& \mathrm{D}$ in the past [9]. Official communication will have a positive impact on regional corporate innovation after five years in their positions [10]. The existing literature mostly analyzed the impact of the replacement of officials on innovation and reached different conclusions, and there was no definite conclusion about the impact of the official communication in different network positions on enterprises innovation. Therefore, the impact of official communication on enterprise innovation is worthy of further exploration.

Finally, based on the theory of political system and complex network of official communication, officials with different levels of communication have different social capital and resources and will have different influences on the formulation and implementation of policies. Therefore, when the degree of official communication is different, the relationship between environmental regulation and enterprise innovation remains to be tested. Based on this, this paper takes all A-share listed companies on the Shanghai and Shenzhen stock exchanges from 2015 to 2017 as the original data to examine the impact of environmental regulations on corporate innovation and then considers the moderating effects of environmental regulations on corporate innovation under different backgrounds of officials' communication. This can explore the influencing factors of enterprise innovation in depth to promote the improvement of enterprises' independent innovation ability, as illustrated in Figure 1.

Compared to existing studies, our research contributes in four major ways. Firstly, based on the Social Network Analysis method, this paper measured the official communication network which reflects "the direct and indirect connections established by the transfer of officials in various cities." Secondly, based on the Factor Analysis method, we also construct an evaluation index system for enterprise innovation through exploratory Factor Analysis of many indicators. Thirdly, from a macroperspective, we explore the main factors of enterprise innovation through two aspects of environmental regulations and official communication, which provides a novel way of further promoting enterprise innovation. Finally, we further discuss the moderating effect of official communication on the relationship between environmental regulations and enterprise innovation. Overall, our study is helpful to further understand the important role

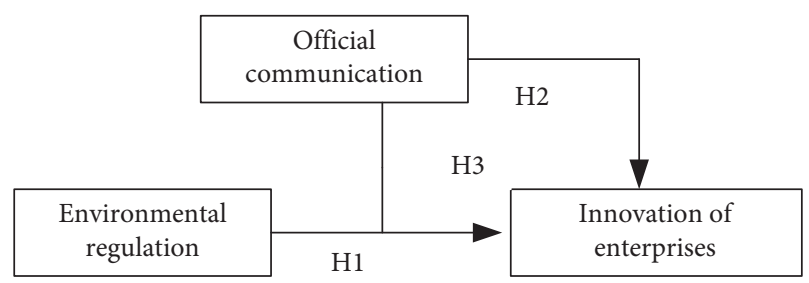

FIgURe 1: Research idea diagram.

of environmental regulation and official communication in promoting enterprise innovation.

\section{Institutional Background}

As the important part of Chinese personnel management systems, exchange system of leading plays an important role. It can promote coordinated regional development and improve governing capacity. With the continuous improvement of Chinese personnel management systems, the CPC Central Committee has paid more and more attention to the exchange system of leading. The Central Committee of the Communist Party of China successively promulgated the "Decision on Implementing the Exchange System of Leading Cadres of the Party and State Organs" (1990), the "Regulations on the Exchange of Party and Government Leading Cadres" (2006), the "Decision of the Central Committee of the Communist Party of China on Strengthening and Improving Some Major Issues of Party Building under the New Situation" (2009), and other documents. On March 11, 2018, the amended constitution of the People's Republic of China clearly stipulated that China adopts the posttenure system for leading cadres, and each term of office and government leadership positions is five years. In March 2019, the Central Committee of the Communist Party of China issued the revised edition of "Working Regulations for Selection and Appointment of Party and Government Leading Cadre," which clearly stated that the exchange system of party and government leading cadres should be implemented. In principle, local party committees and government leading members should serve one term. Those who have served in a position for more than ten years must exchange. If the leading cadres in the party and government organs have served for a long time in the same position, they should be exchanged. As a result, Chinese officials are increasingly communicating with each other, which will also have an impact on local economic and technological development.

At present, the increasingly serious environmental pollution has become the main shackle restricting the construction of ecological civilization in China, so the optimization and reconstruction of environmental regulation system have become a great challenge for the Chinese government. The Environmental Protection Law (Trial) in 1979 marked the beginning of environmental legislation, which was revised in 2014 and then implemented on January 1, 2015. Meanwhile, the National Development and Reform Commission and other government departments issued the "Notice on Adjusting Pollutant Discharge Fee Collection Standards and Other Related Issues" in 2014. A number of 
approaches have been developed to ensure the realization of the binding targets for energy conservation and emission reduction, such as adjusting the pollutant discharge fee collection standard, proposing to strengthen online pollutant monitoring, doubling the charges on enterprises with higher pollutant emission concentrations, and so on. It can encourage enterprises to reduce pollutant emissions and protect the ecological environment. In December 2016, the Standing Committee of the National People's Congress promulgated the "Environmental Protection Tax Law of the People's Republic of China" and officially levied an environmental protection tax in January 2018, which would protect and improve the environment, reduce pollutant emissions, and promote the construction of ecological civilization. In a word, environmental issues are highly valued by the government.

\section{Theoretical Literature Review}

Institution is the key to economic growth and plays a fundamental role in social and economic development, which can better explain the relationship between politics and economy [11]. New institutional economics emphasizes the influence of institutional environment on economic development direction and enterprise behavior [12-14]. Due to the changes in the institutional environment brought by official turnover, on the one hand, the political uncertainty faced by enterprises is increased [15-21]. On the other hand, the government's intervention in enterprises is reduced $[22,23]$. Therefore, as a special institutional arrangement in China, official communication will inevitably influence the behavior of enterprises, including innovation. In addition, although China's market-oriented reform has achieved some results, it has not yet established a fully competitive market economy. To a large extent, the government has the ability and motivation to influence local economic development. According to the spokesmen of the government, the exchange and replacement of local officials will inevitably bring about the change of policy environment and weaken or enhance the influence on enterprise behavior.

The impact of environmental regulation on enterprise innovation has been fully discussed by scholars from two perspectives. Based on the traditional neoclassical theory, scholars believed that strict environmental regulation will inevitably reduce the profit margin of enterprises leading to squeezing out $R \& D$ investment and hindering enterprise innovation [24]. However, based on Porter's hypothesis, other scholars believed that truly effective environmental regulation policies can stimulate enterprises' technology innovation and stimulate enterprises to improve efficiency, thus accelerating innovation activities and economic growth. Therefore enterprises can realize a win-win situation of high product profits and "production" at the same time [25]. In particular, some scholars pointed out that strict environmental policy was one of the important ways for developing countries to gain future competitive advantages [26]. All in all, with the development of economy, scholars generally carry out relevant studies based on the "Porter hypothesis" to deeply analyze the mechanism and effect of environmental regulation on enterprise innovation.

\section{Hypotheses Development}

4.1. Environmental Regulation and Enterprise Innovation. The current mainstream research generally agrees with Porter's hypothesis that well-designed environmental regulation is conducive to the creation of "innovation compensation effect" and "first-mover advantage effect," which will not increase the cost of enterprises but can lead to innovation, generate net income, and thus improve the international competitive advantage of enterprises. Scholars have also verified Porter's hypothesis from an empirical perspective and found that environmental regulation has a certain promoting effect on enterprise innovation [27]. In addition, some scholars have pointed out that the "Porter hypothesis" could be realized only when the environmental regulatory intensity crossed a certain threshold. The main reasons are as follows: in the face of environmental regulation, enterprises will achieve technology innovation by increasing pollution control investment to make up for environmental compliance costs. On the other hand, by improving the process, the production efficiency of enterprises, and reducing the production cost the enterprises can offset the increase of environmental governance cost brought by the regulation itself and gain a competitive advantage. In addition, enterprises which reduce pollution emissions can also get government subsidies, credit, tax breaks, and so on. It can further encourage enterprises to improve innovation. In other words, the improvement of environmental regulation forces enterprises to invest more manpower, material resources, and financial resources to carry out environmental governance, thus reduce the input of other activities of enterprises. This requires enterprises to make full use of various preferential policies, reduce the burden, and rely on technological innovation to reduce the cost of environmental regulation. Based on the above analysis, the following hypothesis is proposed.

Hypothesis 1. Under the same conditions, environmental regulations are conducive to enterprise innovation.

\subsection{Official Communication and Corporate Innovation.}

The governance mechanism of government officials is an important institutional arrangement that determines economic growth. At present, many scholars have studied the impact of official communication on economic growth and pointed out that local official communication could promote economic growth to a certain extent, and the term of officials had an inverted U-shaped relationship with economic growth. Some scholars have systematically evaluated the anticorruption effect of official communication and found that official communication reduced the level of corruption in the region. As an important part of the market, the innovation level of enterprises represents the level of regional economic development to a large extent. Therefore, official 
communication also has a certain impact on the innovation strategy formulated in microenterprises.

When the level of communication among officials is low, it means that officials have been in a certain place for a long time. At present, there is a phenomenon of collusion between local officials and enterprises. The longer the official is in his place, the more stable the alliance of interests he establishes with the enterprise. When the rights of an official are combined with the enterprise, it is easy to breed a large number of corrupt behaviors, which will bring huge costs to business operations and inhibit business innovation. On the other hand, in the official exchange network, officials with a low degree of communication are at a disadvantage in the network. They have less social capital, and the individual self has a weaker potential to mobilize resources through the network. When they are making policies and acquiring resources, their ability to formulate policies and obtain resources is weak. Therefore, the officials cannot obtain favorable social resources for microenterprises' innovation, thereby discouraging the enthusiasm of enterprise innovation activities.

With the level of official communication increasing, it helps to break the interest-based relationship network formed by local officials due to long-term posts in a certain place and reduce official corruption. Therefore, it can promote the fair and reasonable distribution of regional resources. Based on this, enterprises will not worry about the unfairness caused by corruption and promote enterprise innovation. In addition, the replacement of officials will break the network of relations between the government and enterprises and also weaken the motivation of enterprises to build a network of relations, allowing enterprises to invest their own resources in technological innovation activities.

When the level of official communication is too high, it means that the time in a certain area is too short, which can easily lead to policy discontinuity. Enterprises take a waitand-see attitude towards regional policies, thereby inhibiting corporate innovation. Studies have shown that policy uncertainty caused by the replacement of local officials will inhibit local enterprise innovation. In addition, some scholars have found that frequent changes of local officials caused local officials to have problems such as impetuous governance and short-term governance concepts. At this time, the company is unable to grasp the market opportunity. So they are likely to bribe officials, which will cause the company to reduce investment in technological innovation. Based on the above analysis, the following hypothesis is proposed, which is specifically shown in Figure 2.

Hypothesis 2. Under the same conditions, there is an inverted U-shaped relationship between the official communication and enterprise innovation.

4.3. Environmental Regulation and Enterprise Innovation: The Moderating Effect of Official Communication. Under the current institutional environment, local governments have discretionary space for many key resources. Officials with different levels of communication have different social

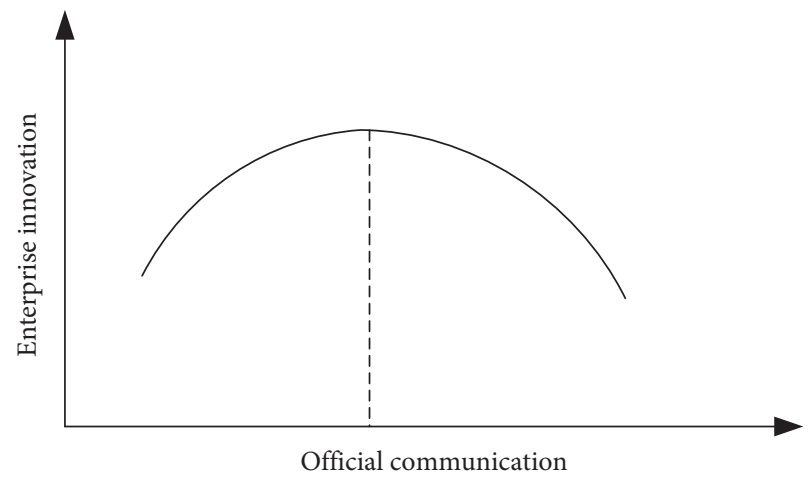

Figure 2: Relationship between official communication and enterprise innovation.

capital and resources, and they will have varying degrees of policy formulation and implementation influences. Therefore, official communication may adjust the relationship between environmental regulation and corporate innovation.

When the level of official communication is low, the resources and experience gained in their network are relatively small, leading to the implementation process of environmental regulations lacking correct guidance, which will weaken the impact of environmental regulations on enterprise innovation and establish an interest-based relationship with the enterprise Internet. Therefore rent-seeking and other corrupt behaviors began to occur frequently. Such politically connected enterprises may receive preferential treatment. Local governments have a tendency to relax their environmental regulations [28]. As a result, the "compliance costs" of enterprises' environmental regulations and policies will reduce. Thereby it is not conducive to stimulating corporate innovation and reducing pollutant emissions.

As the degree of exchange between officials increases, officials will acquire higher social capital and status, having greater control over resources. Consequently, they can promote successful economic and social management experience among regions (or departments) to promote environmental protection. On this occasion the implementation of regulations promotes enterprise innovation. Moreover, the current environmental performance has become one of the important criteria for the promotion and evaluation of officials. In order to be pressured by promotion, local officials will also increase the intensity of local governments' environmental regulations, which in turn will encourage enterprises to carry out technological innovation.

However, when the level of official communication is too high, the term of officials is too short. At this moment, frequent replacements result in companies unable to grasp the government's trends and gain market opportunities. This has led to corporate bribery and corruption, which will squeeze out environmental regulations from technological innovation. In addition, the higher the degree of official communication, the shorter the tenure of officials. Shorter tenure of officials will lead officials to choose a path of promotion with less resistance, where officials often pay 
more attention to economic growth and ignore environmental regulations, resulting in weaker enforcement of environmental regulations, which in turn affects corporate innovation. Based on the above analysis, the following hypothesis is proposed.

Hypothesis 3. Under the same conditions, the regulating effect of official communication on environmental regulation and enterprise innovation shows an "inverted U-shaped" relationship. With the increase of official communication, the influence of environmental regulations on enterprise innovation will be promoted; however, when the official communication reaches a certain degree, the influence of environmental regulations on enterprise innovation will be inhibited.

\section{Research Design}

5.1. Data. In this paper, we selected the enterprises in China's A-share market, including Shenzhen Stock Exchange and Shanghai Stock Exchange, as our samples. The Chinese government revised the Environmental Protection Law of the People's Republic of China in 2014 which has been implemented since January 1, 2015. In addition, a large number of provincial environmental protection policies have been introduced since 2015. Therefore, after 2015, China's Environmental Regulation was strengthened, and its impact on enterprises was significantly increased. As a result, the data after 2015 is less comparable to the data before 2015 . Therefore, this paper takes 2015 as the starting point of empirical test. On the other hand, the data of some indicators in 2018 and the following years are not published, such as the official exchange data and the index $X_{2}$ (R\&D personnel as a percentage of all staff) used in the Factor Analysis method to calculate the innovation ability index of the company. Therefore, the data from 2015 to 2017 were finally selected as the empirical test samples.

Then, according to Tian et al. [29], we dropped those enterprises that suffered consecutive losses (marked as ST or *ST) or where serious information was missing, in order to guarantee the stability and effectiveness of our samples. After selection, we eventually obtained 34,074 enterprise samples in total. In order to avoid the influence of extreme values, the top and bottom of related continuous variables were reduced by $1 \%$. We took the following steps to query and evaluate the data of official communication: First of all, from the website of the Central People's Government of the People's Republic of China (home page-China profile-personnel change query), a list of the names of officials held by municipal party committee secretaries in 320 cities above the prefectural level in China from 2015 to 2017 was obtained. Use the people's net local government officials database to find the official resume as the basic information. Secondly, in order to ensure the authenticity of the network relations of the official's place, all officials of the same name were screened to distinguish whether they were the same person or not, and each official was given a unique ID code. Thirdly, find a list of each official's successive cities, according to the transfer of each municipal party secretary to the post of deputy mayor or above. The matrix outlines a link between different places of service based on official mobility. The value of the matrix $(i, j)$ is 1 if the official A transferred from the city $i$ to the city $j$, otherwise it is 0 , and the diagonal value between the place of office and oneself is 0. Finally, through the large-scale Social Network Analysis software Gephi get the official exchange network index. The enterprise innovation data comes from the Wind database. The related financial index data and the corporate governance index come from the CSMAR database. Data processing and regression analysis are completed with Stata15.0 software.

\subsection{Variables}

5.2.1. Explained Variable: Enterprise Innovation. For measuring enterprise innovation, scholars proposed a variety of methods, such as Analytic Hierarchy Process, Cluster Analysis, Factor Analysis, and Principal Component Analysis [30-34]. Considering Factor Analysis method has low requirement on sample distribution and has little relation with the original variable's dimensionality, this paper uses Factor Analysis method to establish an evaluation model of innovation capability. Factor Analysis method which is used in mathematics to dimensionality reduction recombines the original variables into a new set of independent comprehensive variables and according to the actual need to take out a few less comprehensive variables as much as possible to reflect the original variables of the statistical method. The factors which are extracted by this method can measure the innovation ability of the companies from different perspectives.

Considering that enterprise innovation is a comprehensive concept. Innovation input is the precondition and innovation quality is the effect verification [35]. Based on the research results of Wang et al. [36] and Yu et al. [37], the amount of $R \& D$ investment in the current year is divided by the total assets $\left(X_{1}\right)$ to reflect the amount of $R \& D$ investment in the current year. The proportion of $R \& D$ personnel of all staff $\left(X_{2}\right)$ reflects the investment of enterprise's scientific research personnel. This index is expressed by dividing the number of $R \& D$ personnel employed by the enterprise in the year by the total number of employees in the year. The above two indicators reflect the amount of resources that enterprises have invested in scientific and technological innovation, including the amount of investment and the number of personnel.

There are innovative activities aimed at obtaining other benefits, which are a typical "strategic" behavior." This kind of strategic innovation behavior will reduce the innovation performance and innovation ability of enterprises [38]. Therefore, this paper also chooses the enterprise innovation quality index when constructing the evaluation index of enterprise innovation ability by Factor Analysis method. Referring to the research results of Li et al. [35], invention patents contain a high level of technology, long application requirements, and authorization cycle. So the more invention patents an enterprise owns, the more it attaches importance to high-quality innovation activities and the higher 
the quality of innovation output. Therefore, in this paper, the proportion of invention patent applications in total patent applications $\left(X_{3}\right)$ is used to reflect the quality of innovation output. In addition, the proportion of the number of patents authorized to the number of patent applications $\left(X_{4}\right)$ also reflects the quality of innovation output. The higher the proportion of enterprises that are authorized after applying for patents in that year, the higher the level of patents applied by enterprises and the higher the quality of innovation output. Therefore, this paper adopts Factor Analysis method (Factor Analysis is a statistical method to condense a group of variables into a few factors so as to improve factor interpretation ability) to comprehensively reflect the innovation level of the enterprise from two aspects: innovation input and innovation quality, as shown in Table 1.

In order to eliminate the influence of the dimension and order of magnitude of the data collected, the standardized preprocessing of the data is carried out in this paper. Using SPSS25.0, the principal component is extracted by Principal Component Analysis, and the rotation method is the maximum variance method. The results of the KMO and Bartlett tests (see Table 2) show that the KMO test results are 0.518 , which is suitable for Factor Analysis, and the Sig. value of the test 0.000 indicates the rejection hypothesis.

Principal component analysis is used to extract common factors. As shown in Table 3, the principal component factor is extracted according to the principle that the eigenvalue is greater than 1 . The variance contribution rate of the first two principal component factors is $50.984 \%$ and $36.248 \%$, respectively, and the cumulative variance contribution rate reaches $87.232 \%$. It shows that these two factors can reflect the four-index data completely, reduce the complexity of the data, and achieve the purpose of dimensionality reduction.

We can see from Table 3 that the load value of the first main factor on the $X_{1}, X_{2}$ is very large. Considering these indexes reflect the input ability of enterprise innovation, therefore, the first main factor $F_{2}$ is defined as the enterprise innovation input ability, and the second main factor $F_{1}$ is the ability of enterprise innovation output. In order to increase the explanatory ability of the factor, the maximum variance method is used to rotate orthogonally, and the rotation component matrix of Table 4 is obtained by rotation.

The component score coefficient matrix is obtained by regression method (see Table 4), and the linear expression of the principal factor component can be obtained according to the component score coefficient matrix:

$$
\begin{aligned}
& F_{1}=0.558 X_{1}+0.560 X_{2}-0.049 X_{3}+0.033 X_{4}, \\
& F_{2}=-0.040 X_{1}-0.048 X_{2}+0.525 X_{3}-0.522 X_{4} .
\end{aligned}
$$

From this, we can get the principal component factor score of each enterprise. Then the comprehensive score is calculated according to the variance contribution rate after rotation as the weight.

$$
F=0.46451 F_{1}+0.40781 F_{2} .
$$

Using (1) and (2), the score of $F_{1}, F_{2}$, and $F$ synthesis is calculated to express the innovation ability of the enterprise.

\subsubsection{Explanatory Variables: Official Communication and Environmental Regulation}

(1) Official Communication. Previous studies on the behavior and effect of official governance focus on the individual attributes of officials and the external observable microfactors such as official replacement and term of office. In fact, it is more meaningful to explore the influence of official transfer system on enterprises from the macrolevel and global perspective. This paper attempts to discuss the characteristics and topological structure of official communication network based on complex network theory and discuss the trend of official transfer based on official communication network.

In this paper, the official communication network is defined as a set of direct or indirect connections between different cities due to the flow of officials, which constitutes a directed weighted complex network of official posts. In the official communication network, the node is a certain post place in the network. When quantitatively studying the official communication network, this paper includes all relevant post places as far as possible to ensure the true reliability of the description data. The edge refers to the transfer relationship between the two posts, while the direction of the edge refers to the transfer direction of the official. If the official is transferred from post $A$ to post $B$, the edge points from post $A$ to post $B$, and the weight of the edge refers to the combination of the number of official transfers between the two posts and the city level.

In the official communication network, the posts in the same province can be regarded as a small group, while the posts in neighboring and distant provinces may not establish a link; that is, there is no direct transfer of officials. However, there is always the phenomenon of some officials being transferred across provinces. In this way, a certain degree of connection will be established between the office-holding places without borders, and the office-holding places will form a weak relationship (as shown in Figure 3). Thus, there will be sufficient information and control advantages in the whole network.

The commonly used quantitative tools in complex network analysis are Degree Centrality, Betweenness Centrality, Closeness Centrality, and Eigenvector Centrality [39]. The four indexes can be used to calculate the tightness of the whole network and the importance of each prefecturelevel city in the whole network of official communication. But all the four indicators have advantages and disadvantages. And the network as a whole system should be analyzed from a global point of view, rather than simply with a certain index to analyze. Therefore, this paper uses the logarithm of the four indicators to represent the status of a city in the complex network, so as to comprehensively reflect the official communication degree in a certain place. The higher the index value of a city is, the more important the city is in the complex network, which means the more frequent movement of officials in the city, and more officials will move in or out of the city. And with the movement of officials, the economic policies of the city are more likely to 
TABLE 1: Enterprise innovation evaluation system.

\begin{tabular}{lcc}
\hline Factor analysis & Code name & Evaluation indicators \\
\hline \multirow{2}{*}{ Input $F_{1}$} & $X_{1}$ & Enterprise R\&D input intensity \\
& $X_{2}$ & R\&D personnel as a percentage of all staff \\
\hline \multirow{2}{*}{ Quality $F_{2}$} & $X_{3}$ & The proportion of invention patent applications in total patent applications \\
& $X_{4}$ & Number of patent authorizations as a proportion of patent applications \\
\hline
\end{tabular}

TABLE 2: KMO and Bartlett tests.

\begin{tabular}{lcc}
\hline KMO sampling fitness & & 0.518 \\
$\begin{array}{l}\text { Test of Bartlett's spherical } \\
\text { shape }\end{array}$ & $\begin{array}{c}\text { Approximate } \\
\text { chi-square }\end{array}$ & 106104.211 \\
& $\mathrm{~d} f$ & 6 \\
& Sig. & 0.000 \\
\hline
\end{tabular}

be influenced or influenced by the economic policies of other cities.

The economic meaning and the calculation process of the four indicators are as follows.

(1) Degree Centrality Index

Degree Centrality is the most direct metric to describe Node Centrality in network analysis [40]. The higher the node degree of a node is, the higher the Degree Centrality of the node is, and the more important the node is in the network. It also means that there are frequent changes of officials in the city. The Degree Centrality Index Degree ${ }_{i}$ is calculated by the following formula:

$$
\text { degree }_{i}=\frac{\sum_{j} X_{j i}}{(g-1)} .
$$

The $i$ is a single place of office. The $j$ is a place of office other than the $i$ of the place of office. If there is at least one exchange of officials between the $i$ and the $j$ of office, the $X_{j i}$ is 1 . Otherwise, the $X_{j i}$ is 0 . The index $g$ is the total number of places of service, using $(g-1)$ to eliminate scale differences.

(2) Betweenness Centrality Index

Betweenness Centrality, also known as Intermediate Centrality, refers to the number of times that the current point serves as the short-circuit bridge between two other nodes. In this paper, the number of shortest bridges undertaken by a node is divided by the number of all paths, so as to standardize the data processing. The higher the number of times a node acts as a "bridge," the greater its mediation centrality [41]. It also means that the main leaders of this city are transferred to or transferred from other cities frequently. The Betweenness Centrality Index Betweenness $_{i}$ is calculated by the following formula:

$$
\text { betweenness }_{i}=\frac{\sum_{j<k} g_{j k\left(n_{i}\right)} / g_{j k}}{(g-1)(g-2) / 2},
$$

The $g_{j k}$ is the number of shortcuts that must be taken to connect the $j$ and $k$ of the place of service. The $g_{j k(n i)}$ is the number of $i$ in the shortcut path to the $j$ and $k$ of the office.

(3) Closeness Centrality Index

Closeness Centrality reflects the closeness degree between a node and other nodes in the network, which is to take reciprocal of the shortest distance between the current point and all other nodes. The closer the distance of this point is to all other nodes in the network, the greater the Closeness Centrality and the more it is at the core position of the network [41]. It also means the city officials have a high degree of communication. The Closeness Centrality Index Closeness $_{i}$ is calculated by the following formula:

$$
\text { closeness }_{i}=\frac{g-1}{\sum_{j=1}^{g} d(i, j)} \text {. }
$$

The $d(i, j)$ is the distance from the $i$ to the $j$ of the post in the network. If a given place is not linked to all places of service, the proximity centrality cannot be accurately calculated through the noncomplete relationship. The sum of the number of places directly connected to the place of service is divided and then multiplied by its proportion in the total number of places on the network.

(4) Eigenvector Centrality Index

Eigenvector Centrality is the normalized eigenvector corresponding to the maximum eigenvalue of the adjacency matrix. The greater the centrality of the eigenvector is, the more important the neighbor of the node is, and it is an indicator to measure the importance of its neighbor [42]. The Eigenvector Centrality Index Eigenvector ${ }_{i}$ is calculated by the following formula:

$$
\text { eigenvector }{ }_{i}=\frac{1}{\lambda} \sum_{j} b_{i j} E_{j} .
$$

The $b_{i j}$ is the adjacency matrix. And there is at least one official exchange between the $i$ and the $j$ of the post. Then the $b_{i j}$ is 1 ; otherwise it is 0 . The $\lambda$ is the maximum eigenvector of the $\mathrm{B}$ and $E_{j}$ is the characteristic value of the $j$ centrality of the place of service.

(2) Environmental Regulation. There are five methods to measure the intensity of environmental regulation abroad: The first is measured by the cost of pollution reduction, such as Gray and Shadbegian and Brunnermeier and Cohen 
TABLE 3: Total variance explanation.

\begin{tabular}{|c|c|c|c|c|c|c|c|c|c|}
\hline \multirow[b]{2}{*}{ Composition } & \multicolumn{3}{|c|}{ Initial eigenvalue } & \multicolumn{3}{|c|}{ Extract the square sum of the load } & \multicolumn{3}{|c|}{ Square of rotational load } \\
\hline & Total & $\begin{array}{l}\text { Percentage } \\
\text { variance }\end{array}$ & Cumulative \% & Total & $\begin{array}{l}\text { Percentage } \\
\text { variance }\end{array}$ & Cumulative \% & Total & $\begin{array}{l}\text { Percentage } \\
\text { variance }\end{array}$ & Cumulative \% \\
\hline 1 & 2.039 & 50.984 & 50.984 & 2.039 & 50.984 & 50.984 & 1.858 & 46.451 & 46.451 \\
\hline 2 & 1.450 & 36.24 & 87.232 & 1.450 & 36.248 & 87.232 & 1.631 & 40.781 & 87.232 \\
\hline
\end{tabular}

TABle 4: Common factor variance, rotation component matrix, and score coefficient matrix.

\begin{tabular}{lcccccc}
\hline Composition & \multicolumn{2}{c}{ Common factor variance } & \multicolumn{2}{c}{ Rotating component matrix } & \multicolumn{2}{c}{$\begin{array}{c}\text { Component score coefficient } \\
\text { matrix }\end{array}$} \\
& Initial & Extraction & Initial & Extraction & Initial & Extraction \\
\hline$X_{1}$ & 1.000 & 0.814 & 0.899 & 0.077 & 0.558 & -0.040 \\
$X_{2}$ & 1.000 & 0.815 & 0.901 & 0.064 & 0.560 & -0.048 \\
$X_{3}$ & 1.000 & 0.930 & 0.063 & 0.962 & -0.049 & 0.525 \\
$X_{4}$ & 1.000 & 0.929 & 0.088 & -0.960 & 0.033 & -0.522 \\
\hline
\end{tabular}

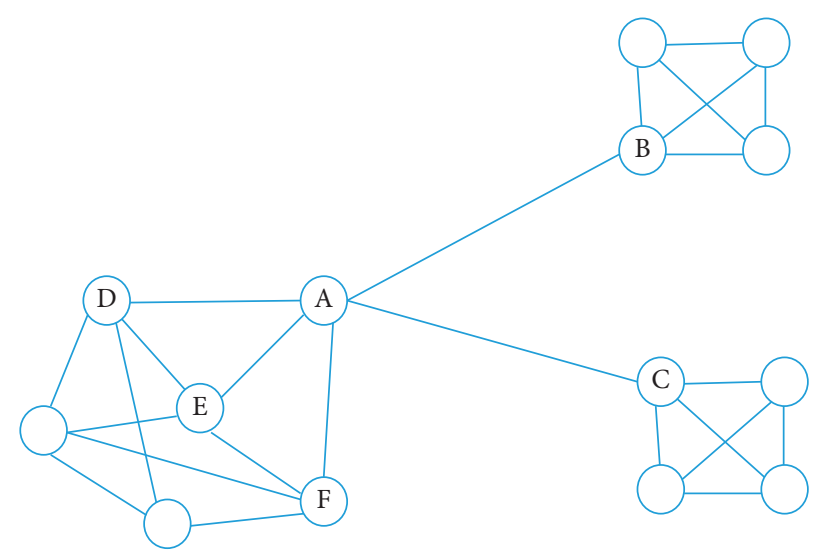

FIGURE 3: Schematic diagram of weak connection relationship.

$[43,44]$; second, replace it with pollution reduction $[45,46]$, such as Rassier and Earnhart [45], Cole and Elliott [46]; third, use pollution facilities operating cost to measure [47], such as Lanoie et al. [47], pollution control investment in the total cost or output value of the enterprise, or pollution control facilities operating costs; the fourth is to measure the number of regulatory systems of industry environmental regulation or the number of inspections and supervision environmental regulation agencies on enterprise sewage discharge [48], such as Berman and Bui [48]; the fifth is expressing [49] the ratio of GDP to energy consumption, such as Zugravu and Kheder. Because of the comprehensiveness of environmental policy and the different types of pollutants, it is difficult to reflect the effect of environmental regulation through a single index. This study uses Data Envelopment Analysis to evaluate environmental regulation.

Data Envelopment Analysis (DEA) is a nonparametric test method developed on the basis of the concept of relative efficiency evaluation [50]. The unit or organization evaluated in DEA is called a decision unit (DMU). DEA constructs the data envelope curve by selecting multiple input and output data of the decision unit, using linear programming, taking the optimal input and output as the production frontier. It can be subdivided into five types: (1) CCR model [50], which was proposed by Charnes, Cooper, and Rhodes in 1978 and can calculate resource allocation efficiency without variable scale compensation; (2) BCC model [51], which was proposed by Banker, Charnes, and Cooper in 1984 and is mainly to calculate the pure technical efficiency, that is, the ratio of technical efficiency to scale efficiency; (3) SEM model [52], in 1993, where Andersen and Petersen proposed that efficiency between different DMU could be compared; (4) SBM model [53], in 2001, where Tone first proposed a DEA model based on relaxation variables; (5) Super-SBM model [54], in 2002, where, through combining with the super-efficiency model, Tone proposed the Super-SBM model, which allows the efficiency value of effective DMU to be greater than or equal to 1 and solves the problem of sorting effective units in the SBM model. The Super-SBM model has two advantages. Firstly, considering the relaxation of input and output indicators, it can be more objective; secondly, the efficiency values of environmental regulation in various regions can be 
distinguished and sorted. Given these advantages, this paper uses this model to evaluate the efficiency of environmental regulation in all provinces. The specific calculation models and steps are as follows.

Suppose there are $N$ existing decision-making units (hereinafter referred to as DMU), and each of them contains three elements, which are input, each containing "a" input elements $M, b_{1}$ three elements of expected output $N^{g}$, and $b_{2}$ nonexpected output. The number of input elements is a. The index $b_{1}$ represents the number of $N^{g}$, and $b_{2}$ is the number of $N^{b}$. According to the Färe, the production possibility set of nonexpected output is constructed as follows:

$$
P=\left\{\left(m, n^{g}, n^{b}\right) \mid m \geq M \lambda, n^{g} \lambda \leq N^{g} \lambda, n^{b} \geq N^{b} \lambda, \lambda \geq 0\right\} .
$$

$\mathrm{DMU}_{O}\left(m_{o}, n^{g}, n^{b}\right)$ environmental regulation intensity evaluation method is shown in

$$
\begin{array}{ll}
\rho^{*}=\min & \frac{1-1 / a \sum_{i=1}^{a} s_{i}^{-} / m_{i 0}}{1+1 / b_{1}+b_{2}\left(\sum_{j=1}^{b_{1}} S_{j}^{g} / n_{j 0}^{g}+\sum_{j=1}^{b_{2}} S_{j}^{b} / n_{j 0}^{b}\right)} \\
\text { s.t. } & m_{0}=M \lambda+S^{-} \\
& n_{0}^{g}=N^{g} \lambda-S^{g} \\
& n_{0}^{b}=N^{b} \lambda-S^{b}, \\
& S^{-} \geq 0, S^{g} \geq 0, S^{b} \geq 0, \lambda \geq 0 .
\end{array}
$$

In formula (8), vector $S=\left(S^{-}, S^{g}, S^{b}\right)$ are the relaxation variables of input elements $M$, expected output $N^{g}$, and nonexpected output $N^{b} . \rho *$ represents the environmental regulation value. When $\rho 0 *=1$, i.e., $S^{-}=0, S^{g}=0, S^{b}=0$, the situation that there is an unexpected output is efficient.

Using formula (8) the calculated results are prone to multiple DMU values of 1 . In order to distinguish, $p 0 *=1$ is treated as follows:

$$
\begin{array}{ll}
\delta^{*}=\min & \frac{1 / a \sum_{i=1}^{a} \bar{m}_{i} / m_{i 0}}{1 / b_{1}+b_{2}\left(\sum_{j=1}^{b_{1}} \bar{n}_{j}^{g} / n_{j 0}^{g}+\sum_{j=1}^{b_{2}} \bar{n}_{j}^{b} / n_{j 0}^{b}\right)} \\
\text { s.t. } \quad \bar{m} \geq \sum_{j=1}^{t} \lambda_{j} m_{j} \\
\\
\overline{n^{g}} \geq \sum_{j=1}^{t} \lambda_{j} n_{j}^{g} \\
\overline{n^{b}} \geq \sum_{j=1}^{t} \lambda_{j} n_{j}^{b}, \\
\bar{m} \geq m_{0}, \overline{n^{g}} \geq n_{0}^{g}, \overline{n^{b}} \geq n_{0}^{b}, \lambda \geq 0 .
\end{array}
$$

By using the Super-SBM model constructed above, the industrial wastewater treatment input, the industrial waste gas treatment input, and the industrial solid waste treatment input are used as the input elements (China Statistical Yearbook (2014-2018)), and the industrial output value and dust, waste water, and general solid waste are used as the expected and nonexpected output of the industry to measure the regional environmental regulation.

5.3. Regression Model. To verify the above hypothesis, model (10) is constructed to verify the hypotheses H1, H2, and H3:

$$
\begin{aligned}
\text { INNO }= & \beta_{0}+\beta_{1} \text { Rotation }+\beta_{2} \text { Rotation }^{2} \\
& +\beta_{3} \text { ER }+\beta_{4} \text { Rotation } \times \text { ER } \\
& +\beta_{5} \text { Rotation }^{2} \times \mathrm{ER}+\text { Control }+\gamma .
\end{aligned}
$$

Among them, INNO measured by the Factor Analysis method represents the innovation level of the enterprise. Rotation and Rotation ${ }^{2}$, respectively, represent official communication and their squared terms, in order to investigate the impact of local officials' communication intensity on enterprise innovation. For testing H1 assumptions, a positive Rotation coefficient is expected; Rotation $^{2}$ coefficient is negative. ER is the environmental regulation index, with a combined score. For testing $\mathrm{H} 2$ assumptions, the projected coefficient is positive. The Rotation $\times$ ER and Rotation ${ }^{2} \times$ ER are the interactions between official communication and environmental regulation to examine the impact of environmental regulation on corporate innovation in different levels of official communication to test hypothesis H3. Moreover, this paper draws on the existing literature to control other variables that may have a significant impact on enterprise innovation, including enterprise size (Size), return on net assets (Roe), shareholding ratio of the largest shareholder (Top1), and assetliability ratio (Debt). The specific definition of variables is shown in Table 5.

\section{Empirical Results and Discussion}

6.1. Descriptive Statistics. The descriptive statistics of the main variables are shown in Table 6.

Table 6 is the descriptive statistical results of the relevant variables. The mean value of enterprise innovation (INNO) is 0.0072 . It shows that the innovation level of enterprises in the selected samples is generally low. The government needs to take measures to encourage enterprises to actively carry out innovative activities. In terms of explanatory variables, the average value of index Rotation is 0.87 . The maximum is 1.96. The minimum is 0.01 . These numbers show that there are obvious differences in the degree of communication between local officials; the max of environmental regulation (ER) is 1.17. And the minimum is 0.001 . It shows that there is a certain gap in the intensity of environmental regulation in various regions. The mean value of this index is 0.05 , indicating that the overall environmental regulation intensity in the region is weak. Control needs to be further strengthened. Besides, the correlation coefficient is low 
Table 5: Definition of variables.

\begin{tabular}{|c|c|c|}
\hline Variant properties & Variable name & Definition and calculation of variables \\
\hline $\begin{array}{l}\text { Interpretative } \\
\text { variables }\end{array}$ & $\begin{array}{l}\text { INNO } \\
\text { Rotation } \\
\text { Rotation }^{2}\end{array}$ & $\begin{array}{c}\text { Enterprise innovation, calculated by Factor Analysis } \\
\text { Official communication, expressed in the logarithm of the sum of the four central indicators in the } \\
\text { official communication network } \\
\text { The square of official communication }\end{array}$ \\
\hline $\begin{array}{l}\text { Explanatory } \\
\text { variables }\end{array}$ & $\begin{array}{l}\text { ER } \\
\text { Rotation } \times \text { ER } \\
\text { Rotation }{ }^{2} \times \text { ER } \\
\text { Size } \\
\text { Roe }\end{array}$ & $\begin{array}{l}\text { Environmental regulation, calculation method as described above } \\
\text { Interaction term used to measure the regulatory effect of official communication on environmental } \\
\text { regulation and enterprise innovation } \\
\text { Natural logarithm of total assets at year end } \\
\text { Net profit/average net assets }\end{array}$ \\
\hline Control variables & $\begin{array}{l}\text { Top1 } \\
\text { Age } \\
\text { Debt }\end{array}$ & $\begin{array}{l}\text { Shareholding ratio of largest shareholder } \\
\text { The age of the enterprise } \\
\text { Total end-of-term liabilities/total end-of-term assets }\end{array}$ \\
\hline
\end{tabular}

TABle 6: Descriptive statistics for key variables.

\begin{tabular}{|c|c|c|c|c|c|c|}
\hline Variable & Observations & Mean & Standard deviation & Minimum value & Maximum value & VIF \\
\hline INNO & 34,074 & 0.0072 & 0.5816 & -0.9942 & 2.6473 & - \\
\hline Rotation & 34,074 & 0.8669 & 0.5167 & 0.0055 & 1.9556 & 1.00 \\
\hline ER & 34,074 & 0.0518 & 0.1036 & 0.0010 & 1.1733 & 1.00 \\
\hline Size & 34,074 & 22.4812 & 1.1894 & 20.1034 & 25.7421 & 1.71 \\
\hline Roe & 34,074 & 0.0652 & 0.0951 & -0.4336 & 0.3022 & 1.09 \\
\hline Top1 & 34,074 & 32.3043 & 13.9188 & 7.84 & 74.18 & 1.02 \\
\hline Age & 34,074 & 10.3426 & 6.5021 & 1 & 24 & 1.28 \\
\hline Debt & 34,074 & 0.4338 & 0.1887 & 0.0683 & 0.9232 & 1.57 \\
\hline
\end{tabular}

Mean VIF: 1.24.

among the pairwise relation numbers of each explanatory variable and the main variable, which indicates that there is no serious multiple collinearity problem between the explanatory variables. The conclusion is consistent with the analysis results of variance inflation factor (VIF) analysis.

6.2. Correlation Analysis. Furthermore, the correlation test between variables is carried out, as shown in Table 7 .

Table 7 shows the correlation analysis of variables. Official communication (Rotation) is significantly positively related to enterprise innovation at the level of $1 \%$. The influence relationship between local official communication and enterprise innovation needs further study. There is a significant negative correlation between environmental regulation (ER) and enterprise innovation (INNO) at the level of $1 \%$, and the specific influence mechanism needs to be deeply excavated. In addition, enterprise size (Size) and enterprise innovation are significantly negatively correlated at the level of $1 \%$, which indicates that the smaller listed companies have more survival pressure and pay more attention to enterprise innovation. The return on net assets (Roe) and enterprise innovation are significant at the level of $1 \%$. The positive correlation shows that profitable enterprises are easier to carry out enterprise innovation activities. The proportion of largest shareholders holding shares (Top1) has significant negative correlation with enterprise innovation at the level of $1 \%$, indicating that equity dispersion is not conducive to enterprise innovation activities. Asset-liability ratio (Debt) and enterprise innovation have significant negative correlation at $1 \%$ level, indicating that high-liability enterprises innovation enthusiasm is weak. In a word, the results of the above correlation test preliminarily show that official communication and environmental regulation can affect the level of enterprise innovation to a certain extent, and the specific impact mechanism needs further regression test. In addition, the correlation coefficient between explanatory variables is low, indicating that the model does not have serious multicollinearity problem.

6.3. Regression Analysis. In order to verify the above hypothesis, model (10) is regressed several times, and the results are shown in Table 8 .

Table 8 shows the regression results of official communication, environmental regulation, and enterprise innovation. Column (1) indicates a significant positive correlation between environmental regulations and enterprise innovation at a significance level of $p<0.05$. In other words, higher environmental regulations make it more conducive for enterprise innovation. Therefore, hypothesis $\mathrm{H} 1$ is supported. In column (2), the regression coefficient between official communication and enterprise innovation is 0.017 at a significance level of $p<0.01$, while the coefficient of the square term of official communication is -0.138 at a 
TABLE 7: Main variable correlation coefficient table.

\begin{tabular}{|c|c|c|c|c|c|c|c|c|}
\hline & INNO & Rotation & ER & Size & Roe & Top1 & Age & Debt \\
\hline INNO & 1.0000 & 0.0059 & $-0.0380^{* * *}$ & $-0.1417^{* * *}$ & $0.0323^{* * *}$ & $-0.0928^{* * *}$ & $-0.0890^{* * *}$ & $-0.1932^{* * *}$ \\
\hline Rotation & $0.0287^{* * *}$ & 1.0000 & $-0.1159^{* * *}$ & $-0.0150^{* * *}$ & $-0.0370^{* * *}$ & $0.0127^{* *}$ & $0.0500^{* * *}$ & $-0.0117^{* *}$ \\
\hline ER & $-0.0232^{* * *}$ & $-0.0119^{* *}$ & 1.0000 & $-0.0880^{* * *}$ & -0.0055 & $-0.0093^{*}$ & $-0.0890^{* * *}$ & $-0.0470^{* * *}$ \\
\hline Size & $-0.1560^{* * *}$ & $-0.0139^{* *}$ & $-0.0454^{* * *}$ & 1.0000 & $0.1410^{* * *}$ & $0.0734^{* * *}$ & $0.4467^{* *}$ & $0.5669^{* * *}$ \\
\hline Roe & $0.0121^{* *}$ & $-0.0191^{* * *}$ & $-0.0486^{* * *}$ & $0.1199^{* * *}$ & 1.0000 & $0.1046^{* * *}$ & $-0.0779^{* * *}$ & $-0.0567^{* * *}$ \\
\hline Top1 & $-0.1086^{* * *}$ & $0.0151^{* * *}$ & $-0.0093^{*}$ & $0.0919^{* * *}$ & $0.0850^{* * *}$ & 1.0000 & $-0.0691^{* * *}$ & $0.0270^{* * *}$ \\
\hline Age & $-0.1063^{* * *}$ & $0.0494^{* * *}$ & $-0.0163^{* * *}$ & $0.4216^{* * *}$ & $-0.0743^{* * *}$ & $-0.0404^{* * *}$ & 1.0000 & $0.3540^{* * *}$ \\
\hline Debt & $-0.2175^{* * *}$ & -0.0065 & $-0.0193^{* * *}$ & $0.5582^{* * *}$ & $-0.1307^{* * *}$ & $0.0274^{* * *}$ & $0.3603^{* * *}$ & 1.0000 \\
\hline
\end{tabular}

Note: the upper right part of the table is Spearman test, and the lower left part is Pearson test. The symbols ${ }^{* * *},{ }^{* *},{ }^{*}$ represent a significant level of 1,5 , and 10 , respectively.

TABLE 8: Regression coefficient tables.

\begin{tabular}{|c|c|c|c|}
\hline Variable & $(1)$ & $(2)$ & (3) \\
\hline ER & $0.079^{* *}(2.565)$ & & $0.160^{* * *}(3.315)$ \\
\hline Rotation & & $0.020^{* * *}(3.485)$ & $0.014^{* *}(2.397)$ \\
\hline Rotation $^{2}$ & & $-0.140^{* * *}(-14.370)$ & $-0.150^{* * *}(-14.106)$ \\
\hline Rotation $*$ ER & & & $-0.175^{*}(-1.682)$ \\
\hline Rotation $^{2} *$ ER & & & $-0.612^{* * *}(-2.778)$ \\
\hline Size & $-0.010^{* * *}(-2.958)$ & $-0.009^{* * *}(-2.684)$ & $-0.009^{* * *}(-2.764)$ \\
\hline Roe & $-0.084^{* * *}(-2.636)$ & $-0.087^{* * *}(-2.724)$ & $-0.085^{* * *}(-2.651)$ \\
\hline Top1 & $-0.002^{* * *}(-11.365)$ & $-0.003^{* * *}(-12.071)$ & $-0.003^{* * *}(-12.075)$ \\
\hline Age & $-0.002^{* * *}(-4.345)$ & $-0.002^{* * *}(-4.179)$ & $-0.002^{* * *}(-4.133)$ \\
\hline Debt & $-0.438^{* * *}(-22.049)$ & $-0.443^{* * *}(-22.379)$ & $-0.442^{* * *}(-22.314)$ \\
\hline _cons & $0.283^{* * *}(3.808)$ & $0.319^{* * *}(4.306)$ & $0.321^{* * *}(4.316)$ \\
\hline $\bar{N}$ & 34,074 & 34,074 & 34,074 \\
\hline$F$ & 277.339 & 276.921 & 247.730 \\
\hline$R^{2}$ & 0.163 & 0.168 & 0.169 \\
\hline
\end{tabular}

Note: $t$ statistics in parentheses; ${ }^{*} p<0.1,{ }^{* *} p<0.05$, and ${ }^{* * *} p<0.001$.

significance level of $p<0.01$. It shows that there is an "inverted U-shaped" relationship between official communication and enterprise innovation. $\mathrm{H} 2$ is obviously supported; that is, with the increase of official communication intensity, the enterprise innovation level presents an inverted U-shaped relationship of first increasing and then decreasing. In addition, according to the regression results, the relationship between official communication and enterprise innovation is

$$
\begin{aligned}
\text { INNO }= & 0.020 * \text { Rotation }-0.140 * \text { Rotation }^{2} \\
& -0.009 * \text { Size }-0.087 * \text { Roe }-0.003 * \text { Top } 1 \\
& -0.002 * \text { Age }-0.443 * \text { Debt }+0.283
\end{aligned}
$$

By taking the derivative of formula (11), the formula for calculating the highest point of INNO value is as follows:

$$
0.02-2 * 0.14 * \text { Rotation }=0 .
$$

It shows that the inflection point of the inverted $\mathrm{U}$-shaped curve is 0.071 . Considering the average official communication is 0.87 , which is far greater than the inflection point of the curve, this indicates that, on average, the influence of official communication on enterprise innovation is on the right side of the inverted U-shaped curve. So official communication in China is too frequent, which reduces enterprises' innovation willingness and ability. There are two possible reasons for this phenomenon. On the one hand, in recent years, the Communist Party of China has stepped up efforts to clean up the work style of leading officials and strengthen anticorruption efforts. Many leading officials have been removed from their posts and prosecuted for incompetence or corruption. This have increased the mobility of officials. On the other hand, the Chinese government has put forward the governing concept of making leading officials younger and reducing the average age of officials. Younger, better educated, and more professional talents become leading cadres. That prompts a growing number of young cadres in all fields and, to a certain extent, increases the degree of official communication. Eventually, the two reasons lead to a greater degree of communication between officials. And the influence of official communication on innovation is on the right side of the curve.

In column (3), the interaction item between official communication and environmental regulation (Rotation $\times$ ER) is significantly negatively correlated with enterprise innovation at the level of $10 \%$. Meanwhile the relationship between the interaction of official communication square and environmental regulation (Rotation $^{2} \times$ ER) and enterprise innovation is a significant negative correlation at the level of $5 \%$. The negative 
coefficient of the product of official communication square and environmental regulation (Rotation ${ }^{2} \times \mathrm{ER}$ ) indicates that the influence of official communication on the relationship between environmental regulation and enterprise innovation ability also presents an inverted U-shape. Increased frequency of official communication first will strengthen the promoting effect of environmental regulation on enterprise innovation. However, with the deepening of official communication and the excessive frequency of official communication, the increase of official communication will inhibit the promotion effect of environmental regulation on enterprise innovation. Considering that the coefficient of the product of official communication and environmental regulation (Rotation $\times \mathrm{ER}$ ) is also negative, it indicates that the inflection point of the influence of official communication on the relationship between environmental regulation and enterprise innovation ability is negative. In practice, official communication index cannot be negative. The influence of official communication on the relationship between environmental regulation and enterprise innovation is inevitably on the right side of the inverted U-shaped curve. Therefore, official communication will inhibit the promoting effect of environmental regulation on enterprise innovation. The result of empirical test is not completely consistent with Hypothesis 3. Considering the long payback period and large investment of innovation, enterprises are reluctant to innovate. So, too frequent official communication degree in China reduces the impact of environmental regulation on enterprise innovation.

Moreover, in terms of the control variables selected in columns (1) to (3), the company size (Size) and the largest shareholder shareholding ratio (Top1) are significantly negatively correlated with the level of enterprise innovation, indicating that the larger the scale, the more dispersed the equity, and the less conducive to enterprise innovation. The correlation between the return on net assets (Roe) and enterprise innovation is significant negative correlation at the level of $10 \%$. It is possible that the enterprises with strong profitability will not pay attention to $R \& D$. The significant negative correlation is between asset-liability ratio (Debt) and enterprise innovation at the level of $1 \%$. The possible reason is that the higher the asset-liability ratio, the greater the debt repayment pressure and the inability to carry out innovative activities.

6.4. Robustness Test. The logarithm of intermediary centrality was chosen as the alternative variable of official communication, and the proportion of R\&D investment in total assets was used to replace the index of enterprise innovation ability obtained by Factor Analysis. Based on these, the regression test was carried out again. It was found that the regression results did not change substantially. The results are shown in Table 9.

6.5. Endogenic Test. In order to avoid the influence of endogeneity of variables on the research conclusions, the PSM-DID method was used in this paper to test endogeneity. This paper takes enterprises from 2012 to 2017 as samples and environmental protection policies in 2015 as exogenous impacts. At the same time, based on the indexes which are size, Roe, Top1, Age, and Debt of the company, the sample of enterprises in high-pollution industries and enterprises in low-pollution industries were matched 1:1 by adopting propensity matching score (PSM). Then, test the difference in innovation ability between enterprises in highpollution industries and those in low-pollution industries after the introduction of environmental protection policies in 2015. Index did represents the industry in which the sample enterprises are located. If it is a high-pollution industry enterprise, $d i d$ is 1 . Conversely, $d i d=0$. Index time represents the year in which the sample enterprise is located. If the year of the sample enterprise is before 2015, then time is 0 ; otherwise, time is 1 . Index treat is the product of time and did. The test results are listed in Table 10. The results show that after stricter environmental protection policies were introduced in 2015, the innovation capacity of highpolluting enterprises improved significantly. It shows that environmental regulation can effectively promote the improvement of enterprise innovation ability. The results are consistent with the conclusion of this paper.

6.6. The Further Test. The impact of environmental regulation and official communication on the innovation ability of different types of firms should be different. This paper further explored the impact of environmental regulation and official communication on enterprises with different pollution levels.

Environmental regulation is mainly aimed at highpolluting enterprises. Therefore, the degree of influence on innovation ability of the high-pollution industry enterprises is higher, while the degree of influence on innovation ability of the low-pollution industry enterprises is lower. However, the level of official communication has an impact on all businesses in the region. Therefore, the impact of official communication on the innovation ability of enterprises in high-pollution industries and those in low-pollution industries should be similar.

Table 11 shows the regression results of impact of environmental regulation and official communication on innovation capability of different types of firms. The empirical test results show that the degree of environmental regulation has a positive impact on the innovation ability of enterprises in high-pollution industries at the significance level of $5 \%$. However, environmental regulation has no significant effect on the innovation ability of enterprises in low-pollution industries. For enterprises in high-polluting industries, the coefficient of Rotation index is significantly positive at the level of $5 \%$, while the coefficient of Rotation ${ }^{2}$ index is significantly negative at the level of $1 \%$, indicating that the influence of official communication on the innovation ability of enterprises in high-polluting industries is in an inverted U-shape. The official communication also has the same influence on the innovation ability of enterprises in low-pollution industries.

The test results show that environmental regulation can significantly promote the innovation ability of enterprises in high-pollution industries but has no significant effect on 
TABLE 9: Regression results of impact of environmental regulation and official communication on enterprises' innovation capability.

\begin{tabular}{|c|c|c|c|}
\hline Variable & $(1)$ & $(2)$ & $(3)$ \\
\hline ER & $0.079^{* *}(2.565)$ & & $0.099^{* * *}(2.679)$ \\
\hline Rotation & & $0.043^{* * *}(7.593)$ & $0.042^{* * *}(7.030)$ \\
\hline Rotation $^{2}$ & & $-0.133^{* * *}(-13.137)$ & $-0.137^{* * *}(-12.588)$ \\
\hline Rotation $*$ ER & & & $-0.008(-0.089)$ \\
\hline Rotation $^{2} * \mathrm{ER}$ & & & $-0.332^{*}(-1.740)$ \\
\hline Size & $-0.010^{* * *}(-2.958)$ & $-0.009^{* * *}(-2.787)$ & $-0.009^{* * *}(-2.815)$ \\
\hline Roe & $-0.084^{* * *}(-2.636)$ & $-0.089^{* * *}(-2.774)$ & $-0.087^{* * *}(-2.739)$ \\
\hline Top1 & $-0.002^{* * *}(-11.365)$ & $-0.003^{* * *}(-12.034)$ & $-0.003^{* * *}(-12.014)$ \\
\hline Age & $-0.002^{* * *}(-4.345)$ & $-0.002^{* * *}(-4.087)$ & $-0.002^{* * *}(-4.109)$ \\
\hline Debt & $-0.438^{* * *}(-22.049)$ & $-0.438^{* * *}(-22.110)$ & $-0.437^{* * *}(-22.053)$ \\
\hline _cons & $0.283^{* * *}(3.808)$ & $0.312^{* * *}(4.209)$ & $0.309^{* * *}(4.151)$ \\
\hline $\bar{N}$ & 34074 & 34074 & 34074 \\
\hline$F$ & 277.339 & 275.053 & 245.899 \\
\hline$R^{2}$ & 0.163 & 0.167 & 0.168 \\
\hline
\end{tabular}

Note: $t$ statistics in parentheses; ${ }^{*} p<0.1,{ }^{* *} p<0.05$, and ${ }^{* * *} p<0.001$.

TABLE 10: The results of PSM-DID test.

\begin{tabular}{lc}
\hline Variable & INNO \\
\hline did & $0.009^{* * *}(3.131)$ \\
Time & $-0.004(-1.285)$ \\
Treat & $-0.012^{* * *}(-2.997)$ \\
Size & $-0.002^{* * *}(-10.964)$ \\
Roe & $-0.026^{* * *}(-13.450)$ \\
top1 & $-0.0002^{* * *}(-16.426)$ \\
Age & $-0.001^{* * *}(-18.775)$ \\
Debt & $-0.033^{* * *}(-28.141)$ \\
cons & $0.100^{* * *}(19.792)$ \\
$N$ & 15089 \\
$F$ & 440.41 \\
$R^{2}$ & 0.2390 \\
\hline
\end{tabular}

TABLE 11: Regression results of impact of environmental regulation and official communication on innovation capability of different types of firms.

\begin{tabular}{|c|c|c|c|c|c|c|}
\hline \multirow{2}{*}{ Variable } & \multicolumn{3}{|c|}{ High-pollution industry enterprises } & \multicolumn{3}{|c|}{ Low-pollution industry enterprises } \\
\hline & (1) & $(2)$ & (3) & $(4)$ & $(5)$ & $(6)$ \\
\hline ER & $0.067^{* *}(2.062)$ & & $0.143^{* * *}(2.888)$ & $0.147(1.601)$ & & $0.364^{*}(1.793)$ \\
\hline Rotation & & $0.014^{* *}(2.513)$ & $0.010(1.626)$ & & $0.054^{* * *}(2.669)$ & $0.039^{*}(1.726)$ \\
\hline Rotation $^{2}$ & & $\begin{array}{l}-0.144^{* * *} \\
(-14.342)\end{array}$ & $\begin{array}{l}-0.152^{* * *} \\
(-14.044)\end{array}$ & & $\begin{array}{c}-0.123^{* * *} \\
(-3.635)\end{array}$ & $\begin{array}{c}-0.144^{* * *} \\
(-3.667)\end{array}$ \\
\hline Rotation $*$ ER & & & $-0.139(-1.333)$ & & & $-0.755(-1.397)$ \\
\hline Rotation $^{2} * \mathrm{ER}$ & & & $-0.568^{* *}(-2.570)$ & & & $-0.867(-0.902)$ \\
\hline Size & $-0.006^{*}(-1.689)$ & $-0.005(-1.512)$ & $-0.005(-1.582)$ & $\begin{array}{c}-0.045^{* * *} \\
(-4.021)\end{array}$ & $\begin{array}{c}-0.041^{* * *} \\
(-3.653)\end{array}$ & $\begin{array}{c}-0.042^{* * *} \\
(-3.727)\end{array}$ \\
\hline Roe & $\begin{array}{c}-0.110^{* * *} \\
(-3.363)\end{array}$ & $\begin{array}{c}-0.107^{* * *} \\
(-3.283)\end{array}$ & $-0.106^{* * *}(-3.241)$ & $0.305^{* * *}(2.627)$ & $0.247^{* *}(2.132)$ & $0.254^{* *}(2.185)$ \\
\hline Top1 & $\begin{array}{c}-0.003^{* * *} \\
(-11.489)\end{array}$ & $\begin{array}{c}-0.107^{* * *} \\
(-3.283)\end{array}$ & $\begin{array}{l}-0.003^{* * *} \\
(-12.255)\end{array}$ & $\begin{array}{c}-0.002^{* * *} \\
(-3.251)\end{array}$ & $\begin{array}{c}-0.002^{* * *} \\
(-3.384)\end{array}$ & $\begin{array}{c}-0.002^{* * *} \\
(-3.374)\end{array}$ \\
\hline Age & $\begin{array}{c}-0.003^{* * *} \\
(-6.327)\end{array}$ & $\begin{array}{c}-0.003^{* * *} \\
(-6.214)\end{array}$ & $\begin{array}{c}-0.003^{* * *} \\
(-6.144)\end{array}$ & $0.005^{* * *}(2.683)$ & $0.005^{* * *}(2.775)$ & $0.005^{* * *}(2.670)$ \\
\hline Debt & $\begin{array}{l}-0.408^{* * *} \\
(-19.834)\end{array}$ & $\begin{array}{l}-0.003^{* * *} \\
(-12.267)\end{array}$ & $\begin{array}{l}-0.408^{* * *} \\
(-19.911)\end{array}$ & $\begin{array}{c}-0.639^{* * *} \\
(-9.704)\end{array}$ & $\begin{array}{c}-0.668^{* * *} \\
(-10.134)\end{array}$ & $\begin{array}{c}-0.663^{* * *} \\
(-10.035)\end{array}$ \\
\hline _cons & $0.013(0.178)$ & $0.045(0.601)$ & $0.046(0.622)$ & $1.012^{* * *}(4.234)$ & $0.991^{* * *}(4.156)$ & $0.998^{* * *}(4.171)$ \\
\hline$N$ & 29393 & 29393 & 29393 & 4681 & 4681 & 4681 \\
\hline$F$ & 168.736 & 173.560 & 141.632 & 134.110 & 128.884 & 112.231 \\
\hline$R^{2}$ & 0.064 & 0.071 & 0.071 & 0.351 & 0.353 & 0.353 \\
\hline
\end{tabular}


enterprises in low-pollution industries. However, the influence of official communication on the innovation ability of enterprises in both high-pollution and low-pollution industries shows an inverted U-shape. This further illustrates the promoting effect of environmental regulation on enterprise innovation and the moderating effect of official communication on the relationship between environmental regulation and enterprise innovation.

\section{Conclusions}

This paper empirically studies the influence of official communication and environmental regulation on enterprise innovation by using the relevant data of all A listed companies in Shanghai and Shenzhen Stock Exchange from 2015 to 2017, the relevant data of China Financial Ecological Environment report, and the manual search of the relevant data of the tenure of municipal party secretaries. As a result, the environmental regulation will significantly promote enterprise innovation. The greater the intensity of environmental regulation, the more conducive it is to promoting enterprise innovation. In addition, there is a significant upside-down curve relationship between official communication and enterprise innovation; that is, with the strengthening of official communication, the inverted $U$ level of enterprise innovation increases first and then decreases. More importantly, official communication reduces the degree of impact of environmental regulation on enterprise innovation. The above conclusions have important implications for optimizing the official communication system, perfecting the environmental regulation policy, and improving enterprise innovation:

(1) Improving environmental regulation policy and fully releasing the positive effect of environmental regulation policy on enterprise innovation: on the one hand, local governments should take improving environmental regulation as a starting point to promote enterprise innovation, implement environmental policies, and strengthen environmental protection; on the other hand, local governments should formulate supporting policies for local environmental protection. Especially in fiscal policy and industrial policy, the problem of insufficient innovation funds should be solved to some extent.

(2) Optimizing the official communication system and fully releasing the positive effect of official communication on innovation: official communication greatly affects their behavior cognition, thought style, and experience, which plays an important role in the formulation of enterprise innovation policy. In particular, with the increase of official communication degree, the ability of enterprise innovation is obviously improved in the early stage. Therefore, on the one hand, we should optimize the appointment system of party and government leading cadres, optimize the members of the leading bodies of local governments, and match the leading cadres with different levels of communication to promote all kinds of cadres. On the other hand, for officials with different communication degrees, different performance appraisal and incentive policies are adopted to guide officials with different communication degrees to promote enterprise innovation. All in all, we should further improve the system of official communication, make its communication effect reach the inflection point of "U-type" curve as soon as possible, and realize the maximum promotion effect of local official communication on enterprise innovation.

\section{Data Availability}

All data generated or analyzed during this study are included within this article and its supplementary information files.

\section{Conflicts of Interest}

The authors declare that there are no conflicts of interest regarding the publication of this paper.

\section{Acknowledgments}

This work was supported by the National Social Science Foundation of China: Study on the Coupling Mechanism and Regional Heterogeneity between Environmental Regulation and Environmental Responsibility Fulfillment of Enterprises (Grant no. 18BGL185) and Hebei Province Universities Hundred Outstanding Innovative Talents Support Program (Grant no. SLRC2019003).

\section{Supplementary Materials}

All data generated or analyzed during this study are included in supplementary material files. (Supplementary Materials)

\section{References}

[1] J. Wen and G. F. Feng, "The nature of heterogeneous institutions and enterprises and independent innovation," Economic Research, vol. 47, no. 3, pp. 53-64, 2012.

[2] D. Yang and X. Liang, "The path to enhance the core competitiveness of China's communication enterprises-from the ZTE and Huawei incidents," Foreign Economic and Trade Practice, vol. 4, pp. 18-21, 2019.

[3] Y. Chen, Z. H. Xuan, and Z. J. Hu, "The building of an innovative country should be transformed to high-quality development," Science and Technology China, vol. 4, pp. 1-3, 2019.

[4] Y. Li, "The core task of building an innovation-oriented country is to give play to the innovation subject role of enterprises," Reference for Economic Research, vol. 26, pp. 15-20, 2015.

[5] G. H. Jiang and P. G. Rao, "Macro-economic policy and micro-enterprise behavior-expanding the new field of accounting and financial research," Accounting Research, vol. 3, pp. 9-94, 2011.

[6] W. Z. Wang and Y. L. Cao, "Political shock, institutional efficiency and corporate innovation-evidence from the change of top officials," Journal of Shanxi University of Finance and Economics, vol. 39, no. 1, pp. 1-14, 2017. 
[7] J. H. Yin, L. L. Zhang, and L. D. Gong, "Does the turnover of local officials affect the innovation of heavy polluting enterprises?-Evidence from key state control wastewater monitoring enterprises," Journal of Beijing Institute of Technology (Social Science Edition), vol. 7, pp. 1-15, 2020.

[8] Q. J. Wang and J. Wen, "Change of local officials and enterprise innovation-a path exploration based on financing constraints and innovation contribution degree," Nankai Economic Research, vol. 3, pp. 198-225, 2019.

[9] S. He and H. J. Li, "Does the replacement of local officials have a "crowding out" effect on enterprise R\&D investment?" Industrial Economy Research, vol. 4, pp. 30-40, 2014.

[10] Z. T. Zhao, "Research on the relationship between longdistance exchanges of local officials and regional innovation in China-based on the evidence of long-distance exchanges between secretaries of provincial party committees and governors," Research and Development Management, vol. 31, no. 5, pp. 148-158, 2019.

[11] D. C. North, Institutions, Institutional Change and Economic Performance, Cambridge University Press, Cambridge, UK, 1990.

[12] D. C. North, R. P. Thomas, and J. L. Shneidman, The Rise of the Western World: A New Economic History, Cambridge University Press, Cambridge, UK, 1973.

[13] A. Shleifer and R. W. Vishny, "Politicians and firms," Quarterly Journal of Economics, vol. 109, no. 4, pp. 995-1025, 1994.

[14] R. La Porta, F. Lopez-de-Silanes, A. Shleifer, and R. W. Vishny, "Law and finance," Journal of Political Economy, vol. 106, no. 6, pp. 1113-1155, 1998.

[15] A. Durnev, The Real Effects of Political Uncertainty: Elections and Investment Sensitivity to Stock Prices, Social Science Electronic Publishing, Rochester, NY, USA, 2010.

[16] B. Julio and Y. Yook, "Political uncertainty and corporate investment cycles," Journal of Finance, vol. 67, no. 1, pp. 45-83, 2012.

[17] Y. K. Xu, X. H. Qian, and W. A. Li, "Political uncertainty, political association and investment in private enterprises-evidence from the change of party secretaries," Management World, vol. 5, pp. 116-130, 2013.

[18] D. Q. Chen, Y. L. Jin, and Z. Y. Dong, "Policy uncertainty, political relevance and enterprise innovation efficiency," Nankai Management Review, vol. 19, no. 4, pp. 27-35, 2016.

[19] D. Q. Chen, Y. S. Chen, and Z. Y. Dong, "Policy uncertainty, market competition and capital allocation," Financial Research, vol. 11, pp. 65-80, 2017.

[20] D. Q. Chen and Y. S. Chen, "Policy uncertainty and earnings management of listed companies," Economic Research, vol. 53, no. 6, pp. 97-111, 2008.

[21] Y. K. Xu, Y. F. Wang, and S. X. An, "Local officials turnover and enterprise staff allocation," Comparison of Economic and Social Systems, vol. 2, pp. 79-89, 2020.

[22] D. Acemoglu, S. Johnson, and J. Robinson, "The rise of Europe: Atlantic trade, institutional change, and economic growth," American Economic Review, vol. 95, no. 3, pp. 546-579, 2005.

[23] C. F. Cao, "Political power transfer and corporate investment: the logic of China," Management World, vol. 1, pp. 143-188, 2013.

[24] K. Palmer, W. E. Oates, and P. R. Portney, “Tightening environmental standards: the benefit-cost or the no-cost paradigm?" Journal of Economic Perspectives, vol. 9, no. 4, pp. 119-132, 1995.
[25] M. E. Porter and C. v. d. Linde, "Toward a new conception of the environment-competitiveness relationship," Journal of Economic Perspectives, vol. 9, no. 4, pp. 97-118, 1995.

[26] P. West and P. Senez, "Environmental assessment of the NAFTA: the Mexican environmental regulation position report prepared for the province of British Columbia, ministry of economic development," Small Business and Trade, pp. 69-70, 1992.

[27] F. Wang, L. Feng, J. Li, and L. Wang, "Environmental regulation, tenure length of officials, and green innovation of enterprises," International Journal of Environmental Research and Public Health, vol. 17, no. 7, p. 2284, 2020.

[28] D. L. Luo and Z. H. Lai, "Investment in heavy polluting enterprises and promotion of local officials-empirical evidence based on 1999-2010 data of prefectural cities," Accounting Research, vol. 4, pp. 42-95, 2016.

[29] X. Tian, S. Chen, J. T. Xu, B. Da, and X. X. Bao, “The impact of environmental regulation on water pollution enterprises in China: an empirical study based on "two control zones" policy," Journal of Beijing University (Natural Science), vol. 55, no. 5, pp. 941-950, 2019.

[30] H. J. Cao, X. Zhao, and S. J. Huang, "Research on evaluation system of enterprise independent innovation capability," China Industrial Economy, vol. 9, pp. 105-114, 2009.

[31] J. Hagedoorn and M. Cloodt, "Measuring innovative performance: is there an advantage in using multiple indicators?" Research Policy, vol. 32, no. 8, pp. 1365-1379, 2003.

[32] A. Jantunen, "Knowledge-processing capabilities and innovative performance: an empirical study," European Journal of Innovation Management, vol. 8, no. 3, pp. 336-349, 2005.

[33] J. Darroch and R. McNaughton, "Absorptive capacity, innovation, and financial performance," Journal of Business Research, vol. 64, no. 12, pp. 1335-1343, 2011.

[34] Y. C. Yu, X. Gu, and Y. J. Chen, "Gravity model, boundary effect and cross-regional technology transfer in China-based on 2009 2013 inter-provincial panel data analysis," Soft Science, vol. 30, no. 7, pp. 15-18, 2016.

[35] W. J. Li and M. N. Zheng, "Substantive innovation or strategic innovation?" Economic Research Journal, vol. 51, no. 4, pp. 60-73, 2016, in Chinese.

[36] H. J. Wang, M. Y. Li, and T. J. Tang, "The drivers of crossindustry arbitrage among real firms and its impact on innovation," China Industrial Economics, vol. 11, pp. 73-89, 2016, in Chinese with English abstract.

[37] M. G. Yu, H. J. Zhong, and R. Fan, "Privatization, financing constraints and firm innovation: evidence from Chinese industrial firms," Financial Research, vol. 4, pp. 75-91, 2019.

[38] J. Q. Li, "Substantive innovation or strategic innovation? Research on multiplayer stochastic evolutionary game model and simulation," Complexity, vol. 2020, Article ID 9640412, 15 pages, 2020.

[39] G. R. Chen, X. F. Wang, and X. Li, Introduction to Complex Network: Models, Structures and Dynamics, Higher Education Press, Beijing, China, 2012.

[40] D. Nock and S. Yang, Social Network Analysis, Shanghai People's Publishing House, Shanghai, China, 2nd edition, 2012.

[41] X. F. Wang, X. Li, and R. Chen, Introduction to Network Science, Higher Education Press, Beijing, China, 2012.

[42] R. Y. Zhao and J. Wnag, "The visual analysis of social network analysis (SNA)," Library and Information Knowledge, vol. 1, pp. 88-94, 2011. 
[43] W. B. Gray and R. J. Shadbegian, "Plant vintage, technology, and environmental regulation," Journal of Environmental Economics and Management, vol. 46, no. 3, pp. 384-402, 2003.

[44] S. B. Brunnermeier and M. A. Cohen, "Determinants of environmental innovation in US manufacturing industries," Journal of Environmental Economics and Management, vol. 45, no. 2, pp. 278-293, 2003.

[45] D. G. Rassier and D. Earnhart, "Does the porter hypothesis explain expected future financial performance? The effect of clean water regulation on chemical manufacturing firms," Environmental and Resource Economics, vol. 45, no. 3, pp. 353-377, 2010.

[46] M. A. Cole and R. J. R. Elliott, "Determining the trade-environment composition effect: the role of capital, labor and environmental regulations," Journal of Environmental Economics and Management, vol. 46, no. 3, pp. 363-383, 2003.

[47] P. Lanoie, M. Patry, and R. Lajeunesse, "Environmental regulation and productivity: testing the porter hypothesis," Journal of Productivity Analysis, vol. 30, no. 2, pp. 121-128, 2008.

[48] E. Berman and L. T. M. Bui, "Environmental regulation and labor demand: evidence from the south coast air basin," Journal of Public Economics, vol. 79, no. 2, pp. 265-295, 2001.

[49] N. Zugravu and S. B. Kheder, "The pollution haven hypothesis: a geographic economy model in a comparative study," SSRN Electronic Journal, vol. 73, 2008.

[50] A. Charnes, W. W. Cooper, and E. Rhodes, "Measuring the efficiency of decision making units," European Journal of Operational Research, vol. 2, no. 6, pp. 429-444, 1978.

[51] R. D. Banker, A. Charnes, and W. W. Cooper, "Some models for estimating technical and scale inefficiencies in data envelopment analysis," Management Science, vol. 30, no. 9, pp. 1078-1092, 1984.

[52] P. Andersen and N. C. Petersen, "A procedure for ranking efficient units in data envelopment analysis," Management Science, vol. 39, no. 10, pp. 1261-1264, 1993.

[53] K. Tone, "A Slacks-based measure of efficiency in data envelopment analysis," European Journal of Operational Research, vol. 130, no. 3, pp. 498-509, 2001.

[54] K. Tone, "A Slacks-based measure of super-efficiency in data envelopment analysis," European Journal of Operational Research, vol. 143, no. 1, pp. 32-41, 2002. 